\title{
Electrogravimetry and Structural Properties of Thin Silicon Layers, Deposited in Sulfolane and Ionic Liquid Electrolytes
}

Steffen Link ${ }^{\S}$, Anna Dimitrova $a^{\dagger}$,Stefan Krischok ${ }^{\dagger}$, Andreas Bund $d^{\S}$, Svetlozar Ivanov ${ }^{{ }^{*}}$

${ }^{\S}$ Electrochemistry and Electroplating Group, Technische Universität Ilmenau

Gustav-Kirchhoff-Straße 6, Ilmenau 98693, Germany

$\dagger$ Institute of Physics and Institute of Micro- and Nanotechnologies

MacroNano, Technische Universität Ilmenau, Ilmenau 98693, Germany

*e-mail: svetlozar-dimitrov.ivanov@tu-ilmenau.de

*e-mail: steffen.link@tu-ilmenau.de 


\section{Electrochemical deposition}
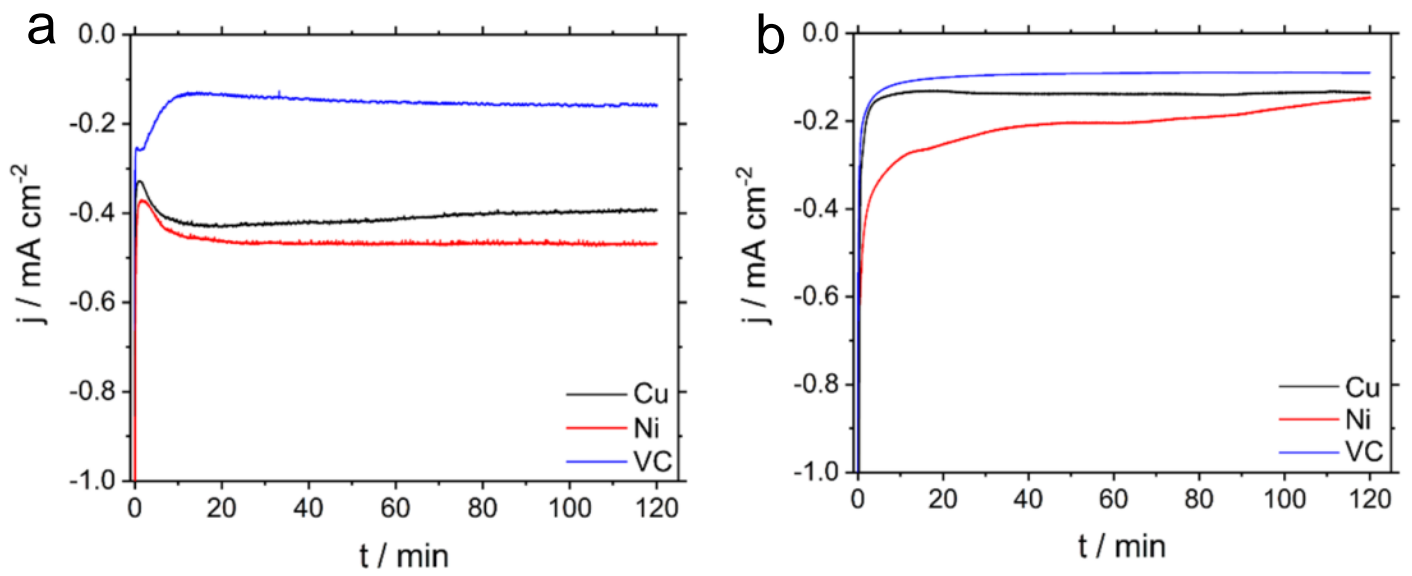

Figure S1. Current transients of the potentiostatic deposition in a) $0.5 \mathrm{M} \mathrm{SiCl}_{4}, 0.1 \mathrm{M} \mathrm{TBACl}$, sulfolane, $\mathrm{E}=-1.5 \mathrm{~V}$ and in b) $0.5 \mathrm{M} \mathrm{SiCl}_{4}$, [BMP][TFSI], $\mathrm{E}=-1.64 \mathrm{~V}(\mathrm{Cu}, \mathrm{Ni})$ and $\mathrm{E}=-1.8$ $\mathrm{V}(\mathrm{GC})$.

The low currents during the deposition are indicative for an inhibited deposition on vitreous carbon compared to the metallic substrates due to the inert behavior and decelerated reaction kinetics of this substrate. Nickel seems to have a stronger catalytic effect on the reduction of silicon tetrachloride than copper, which would explain the accelerated deposition rate.
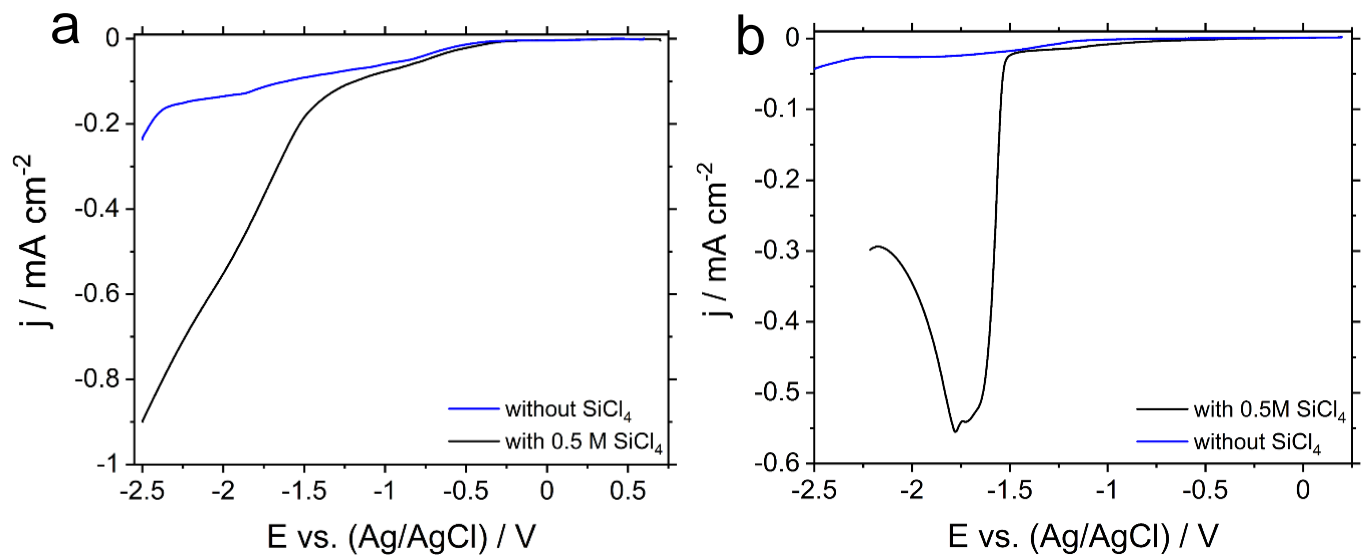

Figure S2. Linear sweep voltammetry, measured on vitreous carbon in a) $0.1 \mathrm{M} \mathrm{TBACl}$, sulfolane electrolyte and in b) [BMP][TFSI], without (blue) and with $0.5 \mathrm{M} \mathrm{SiCl}_{4}$ (black).

$$
v=10 \mathrm{mV} / \mathrm{s}
$$




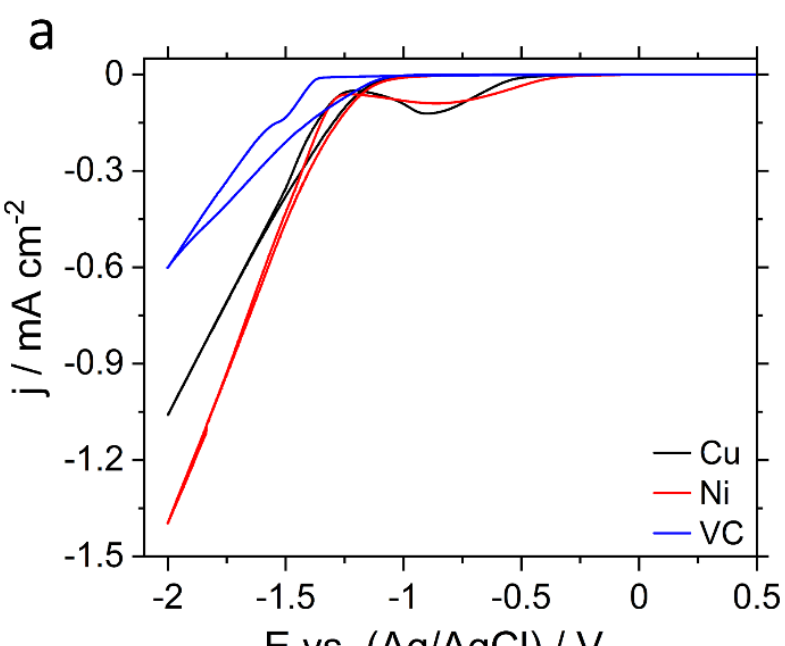

E vs. $(\mathrm{Ag} / \mathrm{AgCl}) / \mathrm{V}$

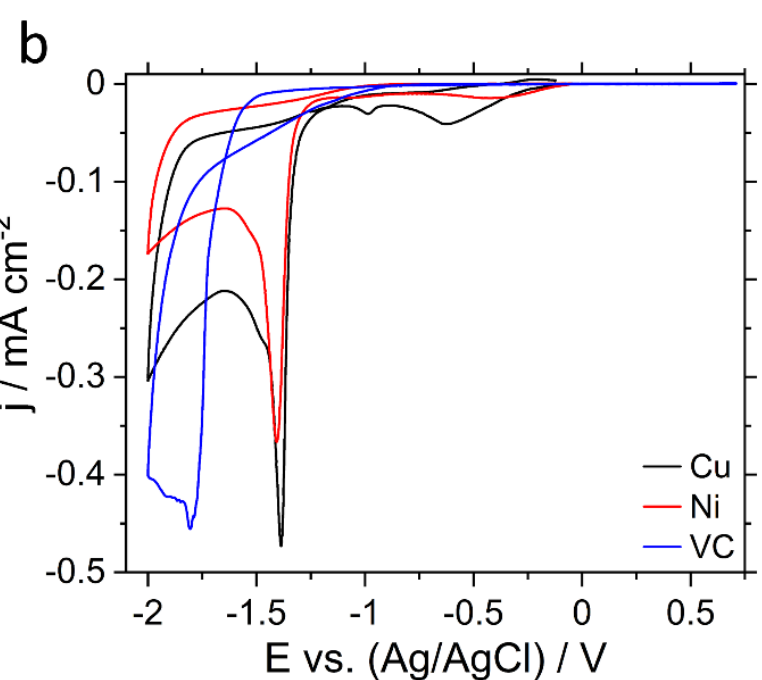

E vs. $(\mathrm{Ag} / \mathrm{AgCl}) / \mathrm{V}$

Figure S3. Cyclic voltammograms (first cycles) of different substrates measured in a) $0.5 \mathrm{M}$ $\mathrm{SiCl}_{4}, 0.1 \mathrm{M} \mathrm{TBACl}$, sulfolane and in b) $0.5 \mathrm{M} \mathrm{SiCl}_{4}$, [BMP][TFSI]. $v=1 \mathrm{mV} \mathrm{s}^{-1}$ 


\section{Wetting behavior}

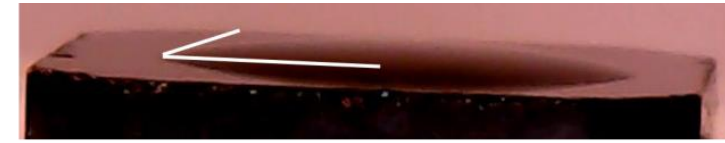

$\alpha=23^{\circ}$ Sulfolane / VC

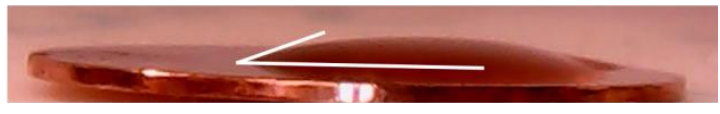

$\alpha=25^{\circ} \quad$ Sulfolane $/ \mathrm{Cu}$

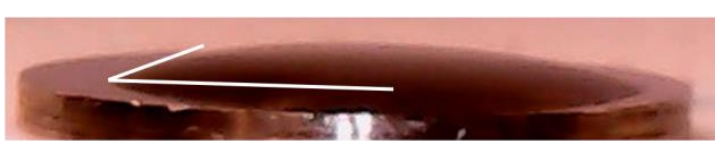

$\alpha=24^{\circ} \quad$ Sulfolane $/ \mathrm{Ni}$
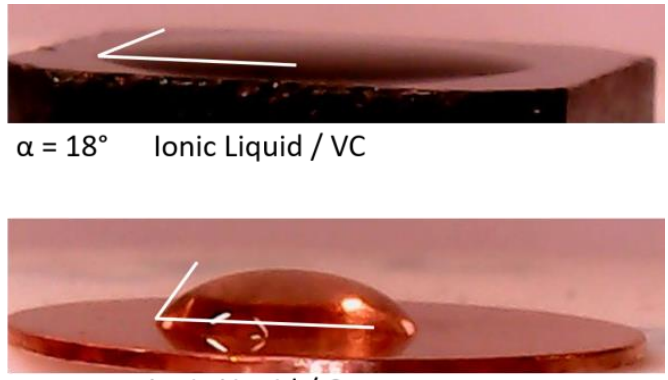

$\alpha=55^{\circ} \quad$ Ionic Liquid / Cu

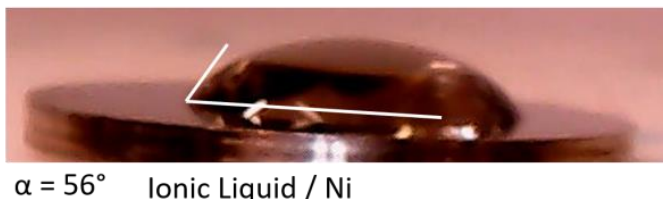

$\alpha=56^{\circ} \quad$ Ionic Liquid / $\mathrm{Ni}$

Figure S4. Cross-sectional optical images, displaying the wetting behavior of the $0.5 \mathrm{M} \mathrm{SiCl}_{4}$ containing sulfolane (left) and [BMP][TFSI] (right) electrolytes.

Wetting behavior of the electrolytes on the used substrates was tested by means of a USB camera (Toolcraft USB microscope 2), inserted into the glove - box. For this purpose, the mirror-polished substrates were positioned straight, at the edge of a big flat plate inside the glove-box, enabling a near cross-sectional imaging of the interfaces (Figure S4). Droplets with equal volume of electrolyte $(25 \mu \mathrm{l})$ were placed on the interfaces and optical images were taken after 1 min equilibration time. After geometric estimation of the wetting angle $(\theta)$ by means of Image $J^{\circledR}$ software, the interfacial energy substrate-liquid $\left(\sigma_{S L}\right)$ was determined by using the Young's equation (eq.1), in accordance with the scheme presented below (Scheme S1). The values for the surface energies of the substrates ( $\sigma_{S G}-\mathrm{Cu}, \mathrm{Ni}$ and VC) and the surface tensions $\left(\sigma_{L G}\right)$ were taken from the literature [1-3]. The surface tensions were approximated to those of the pure solvents $\sigma_{L G, S L}=0.048 \mathrm{Jm}^{-2}$ and $\sigma_{L G, I L}=0.032 \mathrm{Jm}^{-2}[4,5]$.

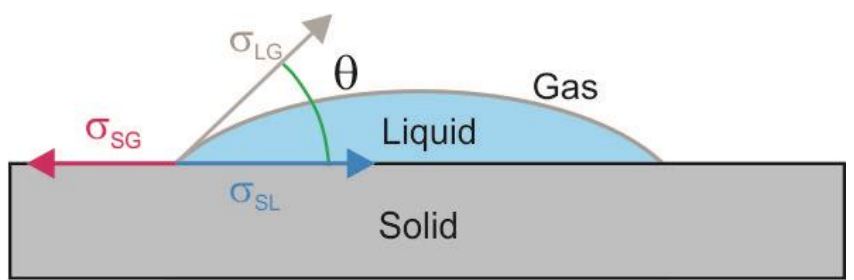

Scheme S1: Graphical representation of surface wetting.

$$
\cos \theta=\frac{\sigma_{S G}-\sigma_{S L}}{\sigma_{L G}}
$$


Table S1. Interfacial energies and wetting angles of $\mathrm{Cu}, \mathrm{Ni}$ and $\mathrm{VC}$ substrates in contact with liquid droplets of sulfolane and [BMP][TFSI] (IL), containing $0.5 \mathrm{M} \mathrm{SiCl}_{4}$.

\begin{tabular}{cccccc} 
Substrate & $\sigma_{S G} / \mathrm{J} \mathrm{m}^{-2}$ & $\sigma_{S L, S u l f} / \mathrm{J} \mathrm{m}^{-2}$ & $\sigma_{S L, I L} / \mathrm{J} \mathrm{m}^{-2}$ & $\theta_{\text {Sulf }} /{ }^{\mathrm{o}}$ & $\theta_{I L} /{ }^{\mathrm{o}}$ \\
\hline $\mathrm{Cu}$ & 1.650 & 1.600 & 1.630 & 25 & 55 \\
\hline $\mathrm{Ni}$ & 2.340 & 2.300 & 2.320 & 24 & 56 \\
\hline $\mathrm{VC}$ & 0.035 & $\rightarrow 0$ & $\rightarrow 0$ & 23 & 18
\end{tabular}

The sulfolane based solution displays very low wetting angles, independently on the substrate type. Furthermore, both electrolytes present low wetting angles on vitreous carbon surface (Table S1).

Due to the high $\sigma_{S G}$ of the metallic substrates and low surface tension of the electrolytes, the interfacial energy solid-liquid $\sigma_{S L}$ remains high in these cases. The two orders of magnitude lower $\sigma_{S G}$ of $\mathrm{VC}$ in combination with the low surface tension of the electrolytes determines an interfacial energy $\sigma_{S L} \rightarrow 0$ when using this substrate. The intention of performing the contact angle experiments is to provide a qualitative information on the wetting behavior of the investigated in this study electrolytes. Although the obtained results are systematically reproducible, high precision devices for contact angle measurements have to be used when necessary. 


\section{XPS characterization}
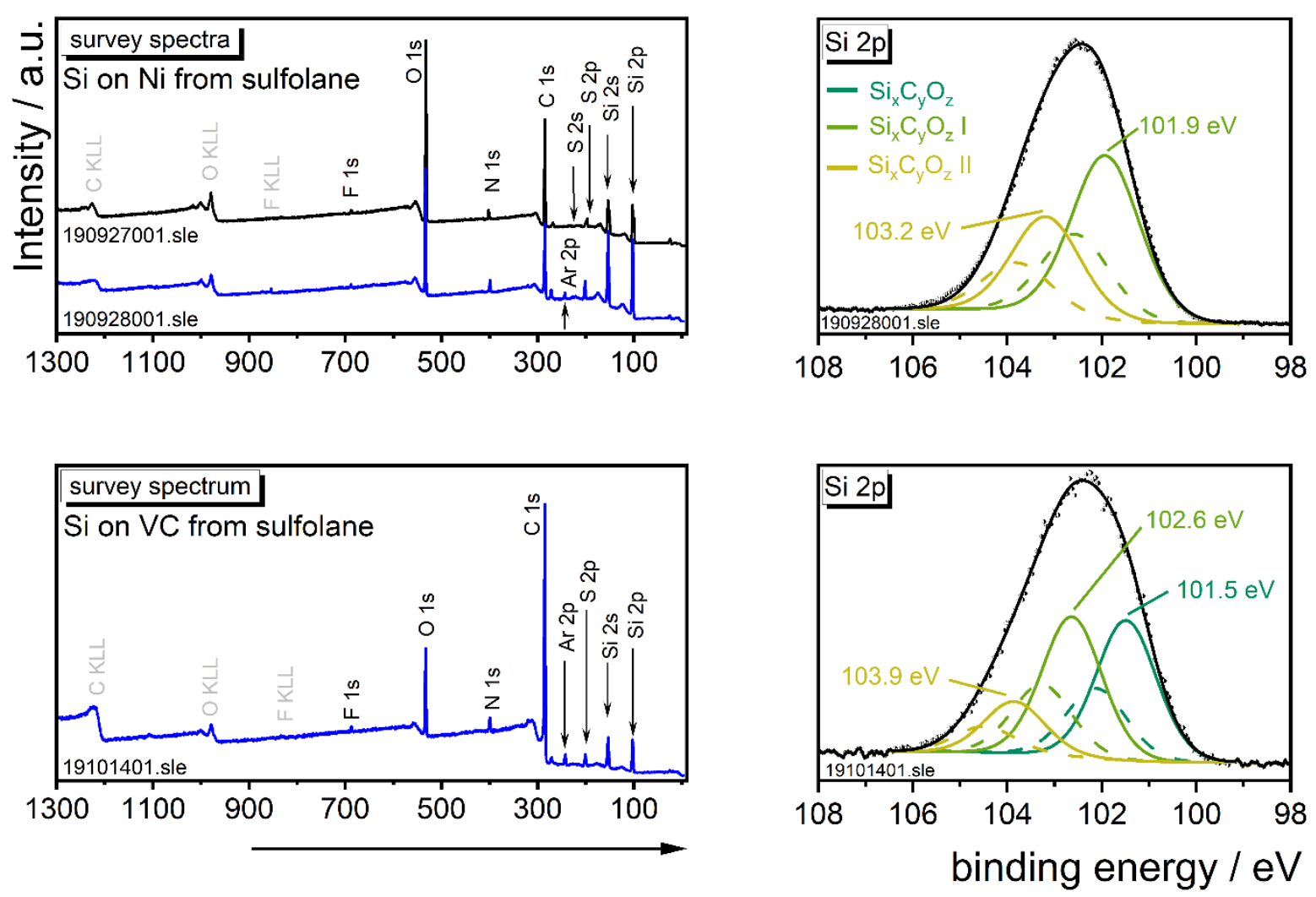

Figure S5. Survey spectra of electrodeposited Si-layer from sulfolane on nickel (upper left panel) and vitreous carbon (lower left panel) and the corresponding Si2p core level peaks after sputtering (right panels, respectively). The survey spectra from the Ni based sample are recorded before and after sputtering (black and blue lines, respectively) and for the vitreous carbon only the spectrum after sputtering is shown. All elements are depicted on the survey spectra and the deconvoluted components from $\mathrm{Si} 2 \mathrm{p}_{3 / 2}$ peaks are shown in respect to their $\mathrm{BE}$ position. The experimental spectrum is shown with open circles, the fitted envelope peak in black, the $2 \mathrm{p}_{3 / 2}$ components in solid lines and the $2 \mathrm{p}_{1 / 2}$ components in dashed lines.

In order to attribute the $\mathrm{C} 1 \mathrm{~s}$ and $\mathrm{O} 1 \mathrm{~s}$-signals to certain species, namely electrolyte or solvent for cleaning, the sample on Ni from SL was rinsed with DMC and the one on VC from SL with hexane.

Because of the high contamination of the layer with carbon products (VC), only the spectrum after sputtering is shown. Three $\mathrm{Si}_{2} \mathrm{p}_{3 / 2}$ core level peaks at $\mathrm{BE}=101.5 \mathrm{eV}, 102.6 \mathrm{eV}$ and $103.9 \mathrm{eV}$ are clearly distinguishable. 
Table S2. XPS quantitative analysis of the samples electrodeposited from sulfolane containing electrolyte on $\mathrm{Ni}-\mathrm{Cu}$ - and $\mathrm{VC}$-substrate before and after sputtering with $\mathrm{Ar}^{+}$. The quantity is present in at $\%$ concentration.

\begin{tabular}{|c|c|c|c|c|c|c|c|}
\hline \multirow{2}{*}{ state } & \multirow{2}{*}{$\mathrm{BE}[\mathrm{eV}]^{*}$} & \multicolumn{2}{|c|}{ nickel } & \multicolumn{2}{|c|}{ copper [6] } & \multicolumn{2}{|c|}{ vitreous carbon } \\
\hline & & $\begin{array}{c}\text { before } \\
\text { sputtering }\end{array}$ & $\begin{array}{c}\text { after } \\
\text { sputtering } \\
\end{array}$ & $\begin{array}{c}\text { before } \\
\text { sputtering }\end{array}$ & $\begin{array}{c}\text { after } \\
\text { sputtering }\end{array}$ & $\begin{array}{c}\text { before } \\
\text { sputtering }\end{array}$ & $\begin{array}{c}\text { after } \\
\text { sputtering }\end{array}$ \\
\hline \multirow{5}{*}{ Si $2 p^{\&}$} & $96.4^{\#}$ & & & 2.4 & & & \\
\hline & $99.4-99.9$ & 15.0 & & 24.4 & & & \\
\hline & $101.7-102.5$ & 17.2 & 35.3 & 15.3 & 31.4 & 0.3 & 11.1 \\
\hline & $102.9-103.8$ & 10.9 & 20.8 & & 19.0 & 0.1 & 10.1 \\
\hline & 104.2 & & & & & & 3.4 \\
\hline \multirow{4}{*}{ C 1s } & 282.3 & & & 5.2 & & & \\
\hline & 284.8 & 24.7 & 14.9 & 20.7 & 10.9 & 72.2 & 46.0 \\
\hline & $285.8-286.3$ & 6.2 & 5.7 & & 8.6 & 20.3 & 14.4 \\
\hline & 286.8-287.1 & & 3.0 & 6.0 & 3.0 & & \\
\hline \multirow{4}{*}{$\mathrm{O} 1 \mathrm{~s}$} & 529.0 & & & 1.2 & & & \\
\hline & 531.1 & & & 4.4 & & & \\
\hline & 532.4-533.4 & 21.1 & 10.6 & 15.8 & 10.3 & 0.3 & 5.5 \\
\hline & $533.8-534.3$ & & 2.1 & & 5.2 & & 1.8 \\
\hline \multirow{5}{*}{$\mathrm{N} 1 \mathrm{~s}$} & 397.5 & 0.1 & & & & & \\
\hline & $398.8-399.3$ & 0.2 & 1.2 & & & 0.6 & 1.5 \\
\hline & $399.8-400.0$ & & 0.5 & & & & 0.6 \\
\hline & 400.9 & & & 0.3 & & & \\
\hline & 402.1 & 1.0 & & & & 2.6 & \\
\hline $\mathrm{S} 2 \mathrm{~s}$ & 227.7 & & & 0.8 & & & \\
\hline \multirow{3}{*}{$\mathrm{Cl} 2 \mathrm{p}$} & 197.8 & 2.0 & & & & & \\
\hline & $200.7-201.7$ & 1.1 & 5.0 & & 0.5 & 1.7 & 3.1 \\
\hline & 202.9 & & & & 0.5 & & \\
\hline \multirow{2}{*}{ F 1s } & 686.9-687.5 & 0.3 & 0.2 & & & 0.3 & 0.3 \\
\hline & 688.6-688.9 & 0.2 & 0.1 & & & 1.5 & 0.1 \\
\hline $\operatorname{Ar} 2 p$ & $242-245$ & & 0.4 & & 1.4 & & 1.0 \\
\hline substrate & & & & 4.5 & 9.3 & & \\
\hline
\end{tabular}

*binding energies for all samples in this contribution were corrected by aligning the $\mathrm{C} 1 \mathrm{~s}$ signal at $284.8 \mathrm{eV}$ \#included for best fit

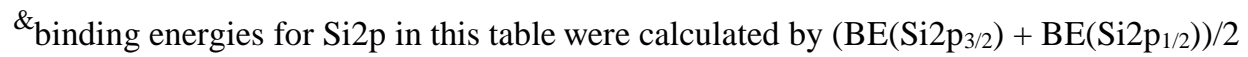



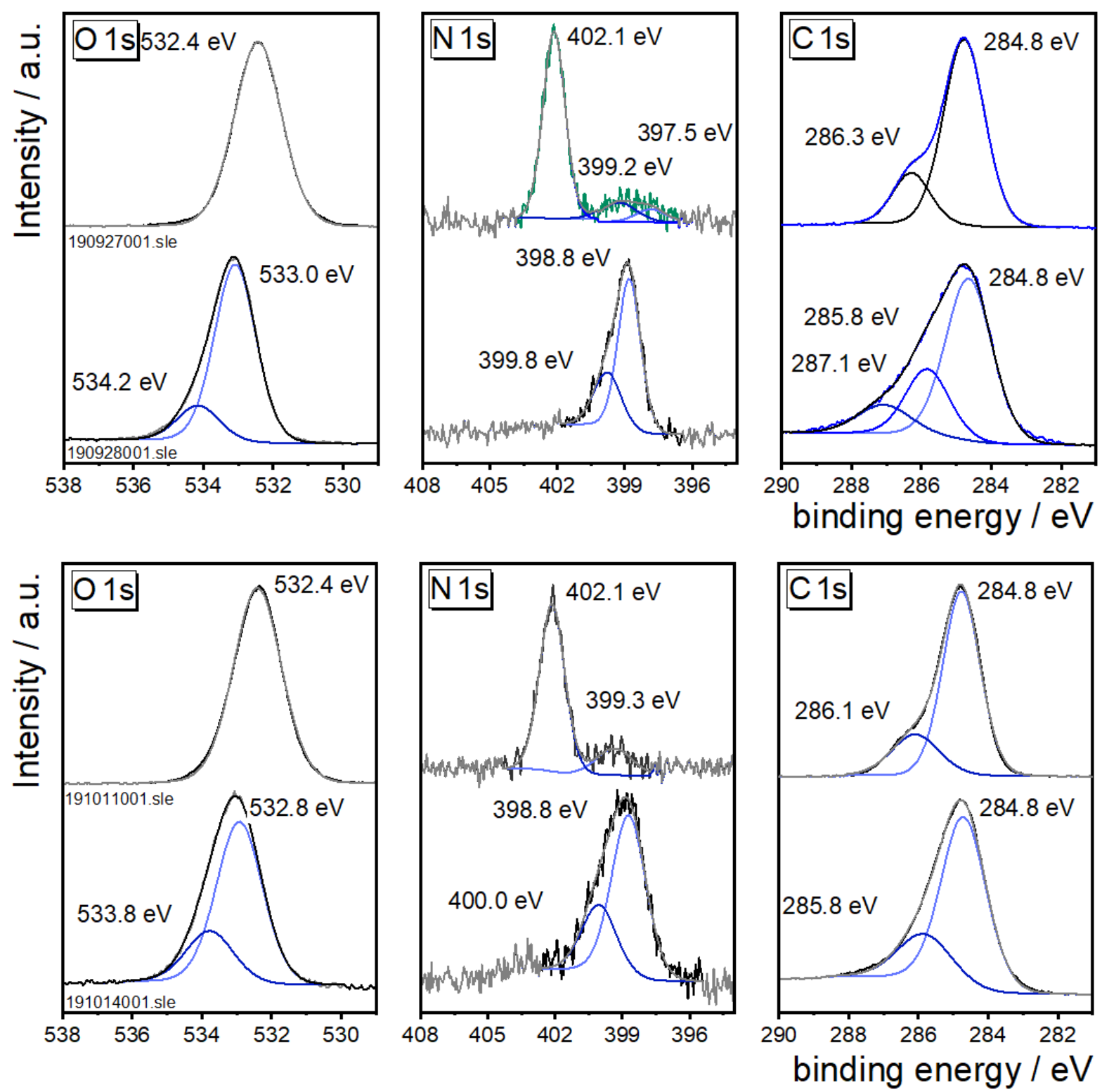

Figure S6 O1s, N1s and C1s core level peaks of Si-electrodeposited layer from sulfolane on $\mathrm{Ni}$-substrate (upper panel) and vitreous carbon (lower panel). The experimental spectrum is shown in grey, the fitted envelope peak in black and all fitted components are colored in blue and labeled according to their $\mathrm{E}_{\mathrm{BE}}$ position.

The presence of carbon and oxygen originate from the electrolyte and the organic carbonate (DMC) used for cleaning after the deposition. $\mathrm{C} 1 \mathrm{~s}$ and $\mathrm{O} 1 \mathrm{~s}$ core level peaks at $\mathrm{BE}=286.3 \mathrm{eV}$ and $\mathrm{BE}=532.4 \mathrm{eV}$ in the $\mathrm{C} 1 \mathrm{~s}$ or $\mathrm{O} 1 \mathrm{~s}$ spectra can be attributed to organic $\mathrm{C}-\mathrm{O}$ or $\mathrm{C}=\mathrm{O}$ moiety, but might also originate from $\mathrm{Si}_{\mathrm{x}} \mathrm{C}_{\mathrm{y}} \mathrm{O}_{\mathrm{z}}$ species. The latter probably arise from the silicon precursor $\left(\mathrm{SiCl}_{4}\right)$, which is stepwise reduced to $\mathrm{Si}^{0}$. These intermediates can further react with the electrolyte or its decomposition products, as discussed in section 4.1.1. As a possible source of oxygen, we do not exclude the oxide layer of the substrate (section 3.2), since major cracks appeared after 2 hours of deposition (see section 4.3). Moreover, a weak signal from the nickel 
substrate can be detected after sputtering for 20 minutes. Along with the detection of Ni, the amount of Si increases to 56.1 at.\% of the overall chemical composition and the contribution of $\mathrm{C}$ and $\mathrm{O}$ decreases (Table $\mathrm{S} 2$ ).

The deconvolution of N1s core level spectrum reveals signals at $\mathrm{BE}=399.0 \mathrm{eV}( \pm 0.3 \mathrm{eV})$, $400 \mathrm{eV}$ and $402 \mathrm{eV}$. Their minor contribution (<3 at.\%) indicate additionally a partial decomposition of the $\mathrm{TBA}^{+}$salt during electrolysis. It has to be mentioned also, that the signal at $402 \mathrm{eV}$ might originate from -Si-N- moiety.
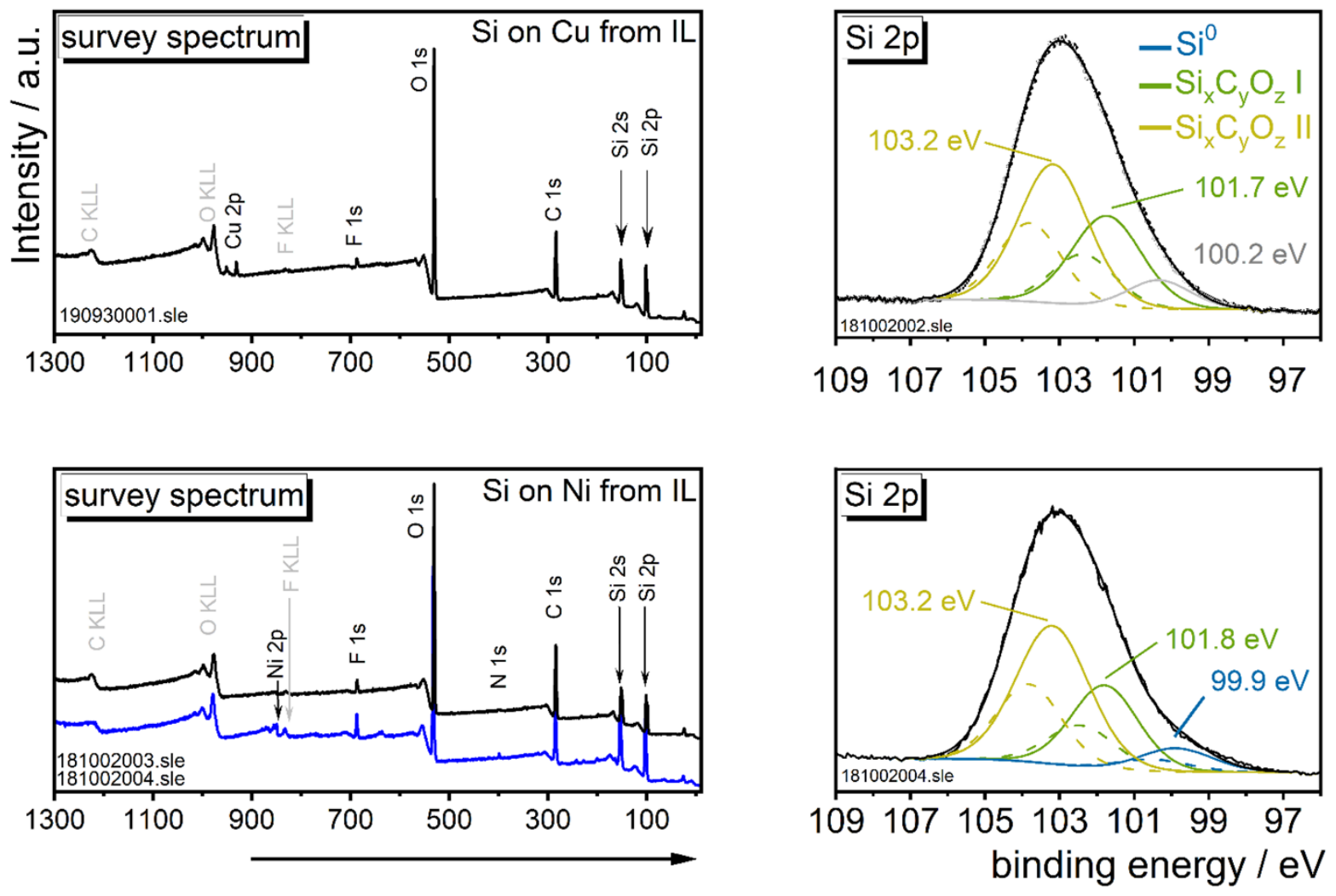

Figure S7. Survey spectra of electrodeposited Si-layer from [BMP][TFSI] on $\mathrm{Cu}$-substrate (upper left panel) and Ni-substrate (lower left panel) and the corresponding Si2p core level peaks after sputtering (right panels, respectively). The survey spectrum from the $\mathrm{Cu}$-based sample is recorded before sputtering and the spectra for the Ni-based sample are shown before and after sputtering (black and blue curves, respectively). All elements are depicted on the survey spectra and the deconvoluted components from $\mathrm{Si} 2 \mathrm{p}_{3 / 2}$ peaks are labeled in respect to the estimated Si species in respect to their BE position. The experimental spectrum is shown with open circles, the fitted envelope peak in black, the $2 p_{3 / 2}$ components in solid lines and the $2 \mathrm{p}_{1 / 2}$ components in dashed lines

For the sample on copper, no difference in the survey spectra before and after sputtering was observed and here only the spectrum before sputtering is shown. 
It should be mentioned that in order to achieve the best fit of Si2p core level spectrum from the sample on $\mathrm{Cu}$ substrate an additional component at $\mathrm{BE}=100.2 \mathrm{eV}(1.6$ at.\%) had to be included in the fitting procedure.

Table S3. XPS quantitative analysis of the samples electrodeposited from [BMP][TFSI] on $\mathrm{Cu}-, \mathrm{Ni}-$ and $\mathrm{VC}$ substrate before and after sputtering with $\mathrm{Ar}^{+}$. The quantity is present in at.\% concentration.

\begin{tabular}{|c|c|c|c|c|c|c|c|}
\hline \multirow[b]{2}{*}{ state } & \multirow[b]{2}{*}{ BE $[\mathrm{eV}]^{*}$} & \multicolumn{2}{|c|}{ nickel } & \multicolumn{2}{|c|}{ copper } & \multicolumn{2}{|c|}{ vitreous carbon [7] } \\
\hline & & $\begin{array}{c}\text { before } \\
\text { sputtering }\end{array}$ & $\begin{array}{c}\text { after } \\
\text { sputtering }\end{array}$ & $\begin{array}{c}\text { before } \\
\text { sputtering }\end{array}$ & $\begin{array}{c}\text { after } \\
\text { sputtering }\end{array}$ & $\begin{array}{c}\text { before } \\
\text { sputtering }\end{array}$ & $\begin{array}{c}\text { after } \\
\text { sputtering }\end{array}$ \\
\hline \multirow{7}{*}{ Si $2 p^{\&}$} & 97.5-100.3\# & 0.3 & & & 1.6 & & \\
\hline & $99.7-100.3$ & 7.5 & 5.2 & 14.5 & & 18.5 & \\
\hline & 100.9 & 14.9 & & & & & \\
\hline & $102.0-102.7$ & & 17.0 & 7.3 & 21.0 & & 3.0 \\
\hline & $103.1-103.5$ & 23.2 & 30.8 & 29.8 & 32.1 & 10.7 & \\
\hline & 104.8 & & & & & & 22.4 \\
\hline & 106.1 & & & & & & 13.4 \\
\hline \multirow{7}{*}{$\mathrm{C} 1 \mathrm{~s}$} & 281.2 & & 0.7 & & & & \\
\hline & $282.8-283.4$ & 3.3 & 1.9 & 2.1 & & 1.8 & \\
\hline & 284.8 & 16.9 & 10.4 & 14.1 & 14.3 & 19.0 & 2.7 \\
\hline & $285.5-286.6$ & 7.7 & 6.2 & 7.1 & & 16.0 & 5.1 \\
\hline & 286.9 & & & & & 7.7 & \\
\hline & $287.6-287.8$ & & 0.8 & & & & 18.0 \\
\hline & 288.8 & & & & & & 9.5 \\
\hline \multirow{5}{*}{$\mathrm{O} 1 \mathrm{~s}$} & $529.7-530.6$ & 7.9 & 0.8 & & & 1.3 & \\
\hline & $531.4-532.1$ & 17.3 & 3.3 & 6.8 & 6.7 & 5.4 & \\
\hline & $532.6-533.4$ & & 19.1 & 17.6 & 22.0 & 18.8 & 1.6 \\
\hline & 534.2 & & & & & & 2.8 \\
\hline & 536 & & & & & & 17.6 \\
\hline $\mathrm{N} 1 \mathrm{~s}$ & $398.9-399.2$ & & 0.9 & & 0.5 & & \\
\hline $\mathrm{Cl} 2 \mathrm{p}$ & 199.6 & & & & & 0.8 & 0.8 \\
\hline \multirow{3}{*}{ F 1s } & 685.1 & 0.1 & 0.1 & & & & \\
\hline & $687.1-688.1$ & 0.6 & 1.9 & 0.5 & 0.7 & & \\
\hline & 688.5 & 0.3 & & & & & \\
\hline $\operatorname{Ar} 2 p$ & $243.6 / 245.8$ & & & & & & $1.7 / 0.4$ \\
\hline substrate & & & 1.0 & 0.4 & 1.0 & & \\
\hline
\end{tabular}

*binding energies for all samples in this contribution were corrected by aligning the $\mathrm{C} 1 \mathrm{~s}$ signal at $284.8 \mathrm{eV}$

\#included for best fit

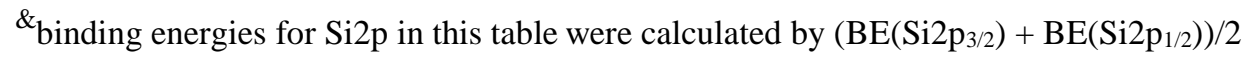




\section{Morphological characterization}
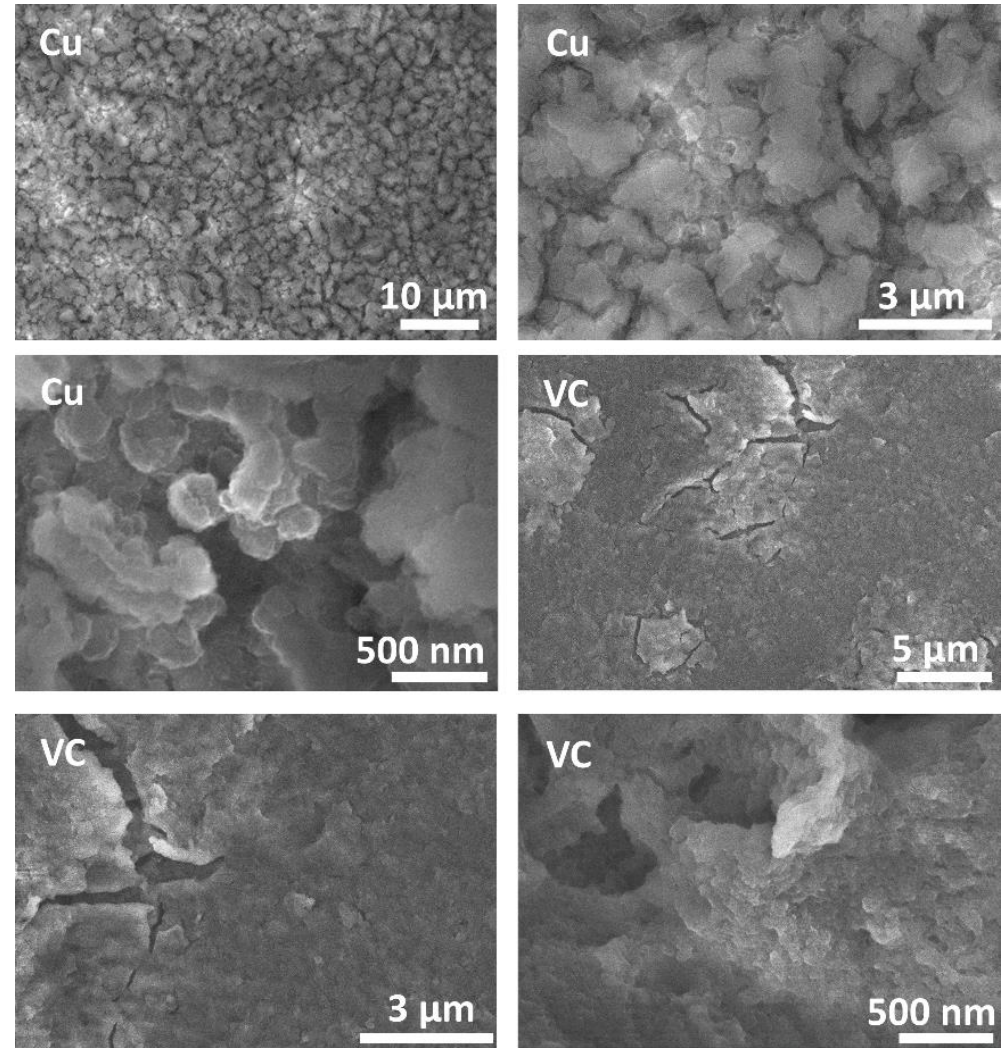

Figure S8. SEM micrographs for silicon electrodeposited on copper and vitreous carbon form $0.5 \mathrm{M} \mathrm{SiCl}_{4}$ in sulfolane with $0.1 \mathrm{M} \mathrm{TBACl}$ at $\mathrm{E}=-1.5 \mathrm{~V}$ for $2 \mathrm{~h}$, respectively.

There are macrocracks with dimensions of about $2.0-3.5 \mu \mathrm{m}$ in length and $180-560 \mathrm{~nm}$ in width visible already at low magnifications for Si layers deposited on copper for $2 \mathrm{~h}$ from sulfolane electrolyte. Zooming in it appears that the different silicon islands from nucleation processes did not grow together completely. The distance between the objects (size: $1.1-1.8 \mu \mathrm{m}$ ) is $1.2-2.2 \mu \mathrm{m}$ in average and hence $\zeta^{*}>\delta$, which is the reason for the increase of $\Delta w$.

The results on vitreous carbon are comparable with the deposit on nickel substrate. The abrasive layer shows homogenously distributed riffs on the surface $(1=2.3-6.3 \mu \mathrm{m}, \mathrm{w}=335-750 \mathrm{~nm})$. At higher magnifications, circular figures in the range of 50 to $150 \mathrm{~nm}$ can be detected.

In consequence of the rough Si layers and the contact with air during transport to the SEM it was not possible to get a good cross-sectional image and to determine the exact thickness. It varies between $700 \mathrm{~nm}$ and $900 \mathrm{~nm}$ after deposition for about $2 \mathrm{~h}$. These results are similar to silicon obtained from other organic media like tetrahydrofurane or acetonitrile $[8,9]$. 

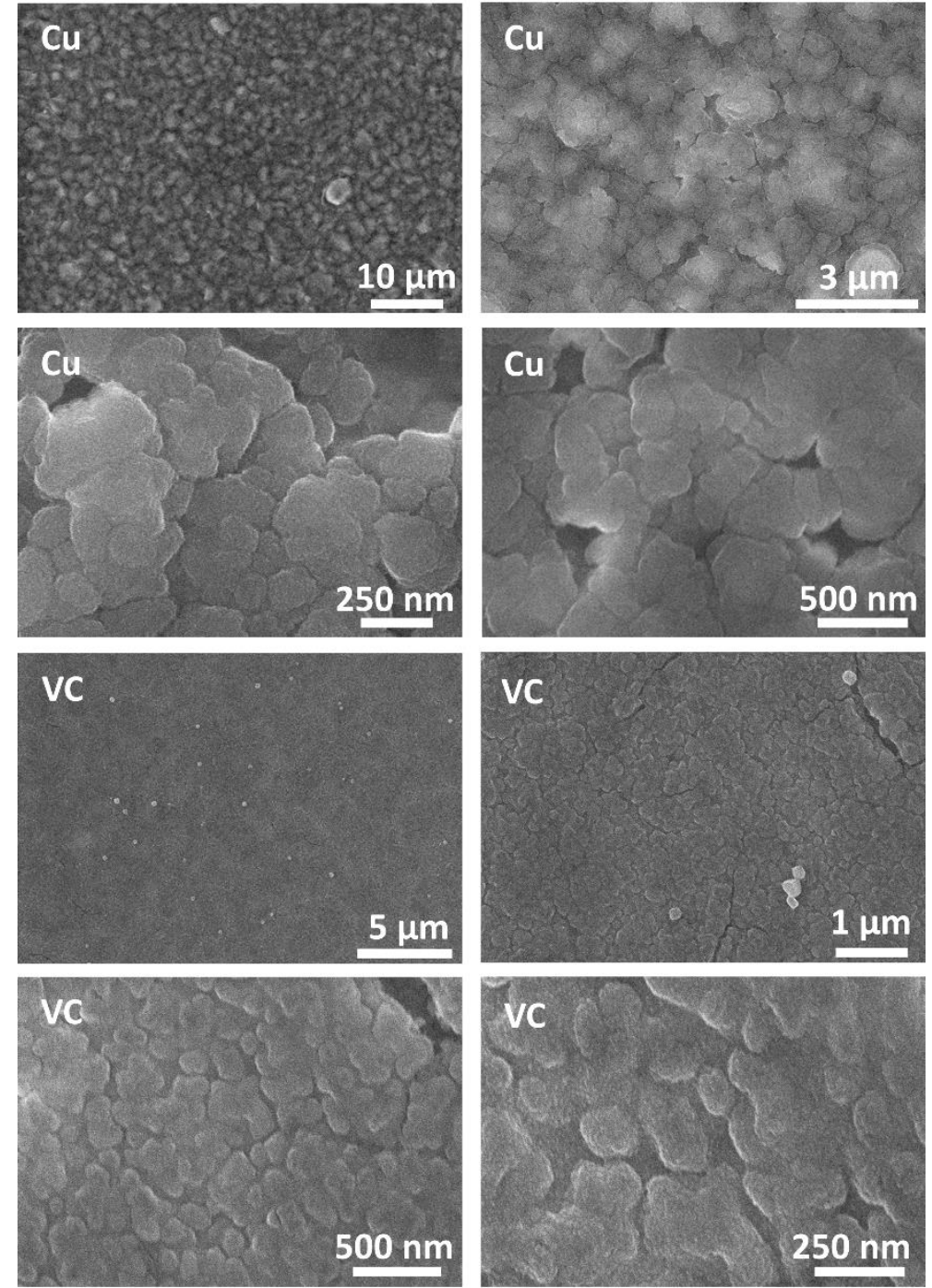

Figure S9. SEM analysis of electrodeposited silicon from $0.5 \mathrm{M} \mathrm{SiCl}_{4}$ in [BMP][TFSI] on $\mathrm{Cu}$ $(\mathrm{E}=-1.64 \mathrm{~V})$ and $\mathrm{VC}(\mathrm{E}=-1.8 \mathrm{~V})$ for $2 \mathrm{~h}$, respectively.

Similar to $\mathrm{Si}$ on copper obtained from sulfolane electrolyte, the layers deposited from [BMP][TFSI] are rough with big voids between the single irregular shaped figures. The size of the objects varies between 0.47 and $1.64 \mu \mathrm{m}$ and the extension of the cracks is at least $1.1 \mu \mathrm{m}$. The bottom four images of figure S9 exhibit a smooth and dense silicon layer on vitreous carbon. On the high magnification images, agglomerated objects of an indefinable shape in the range of $100 \mathrm{~nm}$ to $500 \mathrm{~nm}$ and some minor cracks of $60-110 \mathrm{~nm}$ in width are clearly visible. These results accord quite well with the literature [10,11, 12,13]. Only the particle size for silicon on gold is with less than $100 \mathrm{~nm}$ [13] lower than on the substrates used in this study. From cross-sections (Figure S10) we obtained the thickness of the deposits, which is due to the rough morphology very inhomogeneous and ranges from 0.65 to $1 \mu \mathrm{m}$ for layers deposited to a charge density of $1 \mathrm{C} / \mathrm{cm}^{2}(\mathrm{t} \approx 2 \mathrm{~h})$. 


\section{$1 \mathrm{~mm} /$ \\ $0.65 \mu \mathrm{m}$}

Figure S10. Cross-sectional image of silicon deposited on copper in [BMP][TFSI] till a charge of $1 \mathrm{C} / \mathrm{cm}^{2}(\mathrm{t} \approx 2 \mathrm{~h})$ was reached $-\mathrm{E}=-1.64 \mathrm{~V}$.

\section{References:}

[1] Vitos, L., Ruban, A.V., Skriver, H.L., Kollar, J., The surface energy of metals, Surf. Sci. (1998) 411(1-2), 186-202.

[2] Hulaa, R., Edtmaiera, C., Holzwebera, M., Huttera, H., Eisenmenger-Sittner, C., The wetting behaviour of silver on carbon, pure and carburized nickel, cobalt and molybdenum substrates, Appl. Surf. Sci. (2010) 256(14), 4697-4701.

[3] Clark, E., Yeske, R., Birnbaum, H., The Effect of Hydrogen on the Surface Energy of Nickel, Metall. Trans. A (1980) 11A, 1903-1908.

[4] Kelayeh, S., Jalili, A., Ghotbi, C., Hosseini-Jenab, M., Taghikhani, V., Densities, Viscosities, and Surface Tensions of Aqueous Mixtures of Sulfolane + Triethanolamine and Sulfolane + Diisopropanolamine, J. Chem. Eng. Data, (2011) 56, 4317-4324.

[5] Kolbeck, C., Lehmann, J., Lovelock, K. R. J., Cremer, T., Paape, N., Wasserscheid, P., Fröba, A. P., Maier, F., Steinrück, H.-P., Density and Surface Tension of Ionic Liquids, J. Phys. Chem. B 2010, 114, 17025-17036.

[6] Link, S., Ivanov, S., Dimitrova, A., Krischok, S., Bund, A. Electrochemical Deposition of Silicon From a Sulfolane-Based Electrolyte: Effect of Applied Potential. Electrochem. Commun. 2019, 103, 7-11.

[7] Link, S., Ivanov, S., Dimitrova, A., Krischok, S., Bund, A. Understanding the Initial Stages of Si Electrodeposition Under Diffusion Kinetic Limitation in Ionic Liquid-Based Electrolytes. J. Cryst. Growth 2020, 531, 125346, 1-6.

[8] Munisamy, T. and Bard, A. J. Electrodeposition of Si From Organic Solvents and Studies Related to Initial Stages of Si Growth. Electrochimi. Acta 2010, 55(11), 3797-3803. 
[9] Zhao, G., Meng, Y., Zhang, N., Sun, K. Electrodeposited Si Film With Excellent Stability and High Rate Performance for Lithium-Ion Battery Anodes. Mater. Lett 2012, 76, 55-58.

[10] Vlaic, C. A., Ivanov, S., Peipmann, R., Eisenhardt, A., Himmerlich, M., Krischok, S., Bund, A. Electrochemical Lithiation of Thin Silicon Based Layers Potentiostatically Deposited From Ionic Liquid. Electrochim. Acta 2015, 168, 403-413.

[11] Komadina, J., Akiyoshi, T., Ishibashi, Y., Fukunaka, Y., Homma, T. Electrochemical Quartz Crystal Microbalance Study of Si Electrodeposition in Ionic Liquid. Electrochim. Acta 2013, 100, 236-241.

[12] Tsuyuki, Y., Huynh, T. A. P., Komadina, J., Fukunaka, Y., Homma, T. Electrochemical Quartz Crystal Microbalance, X-ray Photoelectron Spectroscopy, and Raman Spectroscopy Analysis of SiCl4 Reduction in Ionic Liquids. Electrochim. Acta 2015, 183, 49-55.

[13] Pulletikurthi, G., Lahiri, A., Carstens, T., Borisenko, N., El Abedin, S. Z., Endres, F. Electrodeposition of Silicon From Three Different Ionic Liquids: Possible Influence of the Anion on the Deposition Process. J. Solid State Electr. 2013, 17(11), 2823-2832. 